\title{
lodine and iron status of pregnant women in Lubumbashi, Democratic Republic of Congo
}

\author{
Laurence Habimana $^{1}{ }^{*}$, Kabange E Twite ${ }^{2}$, Pierre Wallemacq ${ }^{1}$, Philippe De Nayer ${ }^{1}$, \\ Chantal Daumerie ${ }^{1}$, Philippe Donnen ${ }^{3}$, Muenze K Kalenga ${ }^{2}$ and Annie Robert ${ }^{1, *}$ \\ 'Université Catholique de Louvain, Pôle Epidémiologie et Biostatistique, Institut de Recherche Expérimentale et \\ Clinique Brussels, Ecole de Santé Publique, Clos Chapelle-aux-Champs 30, EPID B1.30.13, BE-1200 Bruxelles, \\ Belgium: ${ }^{2}$ Université de Lubumbashi, Faculté de Médecine, Lubumbashi, DR Congo: ${ }^{3}$ Université Libre de \\ Bruxelles, Ecole de Santé Publique, Brussels, Belgium
}

Submitted 16 April 2012: Final revision received 8 September 2012: Accepted 7 November 2012: First published online 16 January 2013

\begin{abstract}
Objective: Adequate iodine and Fe intakes are imperative during pregnancy to prevent fetal defects, but such data are not available in the Democratic Republic of Congo. We aimed to assess iodine and Fe status in pregnant women from Lubumbashi.

Design: Cross-sectional study. We measured urinary iodine concentration (UIC) in random urine samples using a modified Sandell-Kolthoff digestion method; the WHO reference medians were used to classify iodine intake as deficient, adequate, more than adequate or excessive. Serum ferritin concentrations were measured by immunoenzymatic assay and considered insufficient when $<12 \mathrm{ng} / \mathrm{ml}$.

Setting: Maternity units from rural, semi-urban and urban areas of Lubumbashi, Democratic Republic of Congo.

Subjects: Two hundred and twenty-five randomly selected pregnant women attending prenatal consultation, seventy-five postpartum women and seventy-five non-pregnant women as controls.

Results: Overall median UIC in pregnant women was 138 (interquartile range: 105-172) $\mu \mathrm{g} / \mathrm{l}$, indicating iodine deficiency, whereas postpartum and nonpregnant women had adequate iodine intake: median UIC $=144 \mu \mathrm{g} / \mathrm{l}$ and $204 \mu \mathrm{g} / \mathrm{l}$, respectively. Median UIC values were lower in late pregnancy than in early pregnancy: in the first, second and third trimester respectively $255 \mu \mathrm{g} / 1,70 \mu \mathrm{g} / \mathrm{l}$ and $88 \mu \mathrm{g} / \mathrm{l}$ in the rural area; $306 \mu \mathrm{g} / \mathrm{l}, 166 \mu \mathrm{g} / 1$ and $68 \mu \mathrm{g} / \mathrm{l}$ in the semi-urban area; and $203 \mu \mathrm{g} / 1,174 \mu \mathrm{g} / 1$ and $99 \mu \mathrm{g} / 1$ in the urban area. Fe was insufficient in $39 \%$ of pregnant women compared with $21 \%$ of non-pregnant and postpartum women. In the third trimester, deficiencies in both iodine and Fe were high: $40 \%$, $12 \%$ and $18 \%$ in the rural, semi-urban and urban areas, respectively.

Conclusions: Our data suggest that pregnant women are at risk of iodine and Fe deficiencies in Lubumbashi. Country policies fighting against iodine and Fe deficiencies during pregnancy should be reinforced.
\end{abstract}

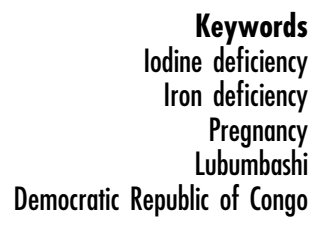

Iodine is a trace element essential for the synthesis of thyroid hormones. Thyroid hormones in turn play a key role in the development of the fetal brain and central nervous system. A deficit in iodine has various consequences called iodine-deficiency disorders. In children and adults, iodine deficiency causes goitre and hypothyroidism. In pregnant women, it brings miscarriages, hypothyroxinaemia and hypothyroidism. In the fetus, iodine deficiency can induce stillbirth, prematurity, congenital anomalies, psychomotor defects, neurological and intellectual deficiency, or cretinism $^{(1)}$.

During the first trimester of pregnancy iodine renal clearance increases, leading to a depletion of iodine.
Furthermore, the demand for thyroid hormones is increased due to the oestrogenic milieu and the transfer of thyroid hormones to the fetus, which does not have a functional thyroid gland yet. Later in pregnancy, the fetus takes iodine from the mother to synthesize thyroid hormones. An adequate iodine intake is imperative to achieve and maintain equilibrium until the term of pregnancy $^{(2)}$ and to prevent health defects in the fetus.

$\mathrm{Fe}$ and iodine deficiencies often coexist ${ }^{(3,4)}$, and both are frequent during pregnancy. Although there are no more menstrual losses during pregnancy, Fe requirements are increased because of the expansion of the red blood cell mass and the increased transfer to the fetus and 
placental structures ${ }^{(5)}$. Fe requirements, as well as iodine needs, gradually increase through gestation from the first to the third trimester of pregnancy ${ }^{(6)}$. The effects of maternal Fe deficiency on the fetus and the child, and the impact of Fe supplementation on them, are still a subject of controversy ${ }^{(7)}$, but the hypothesis is that low maternal Fe stores could induce preterm delivery, low birth weight and Fe deficiency in children ${ }^{(8)}$. Early Fe supplementation during pregnancy is an effective treatment against anaemia in pregnant women. Fe supplementation led to better efficacy in programmes conducted to correct iodine deficiency in children ${ }^{(4)}$, leading to the conclusion that Fe deficiency potentially impairs thyroid metabolism. It was also confirmed that in pregnancy Fe deficiency and maternal thyroid status are associated ${ }^{(3,9)}$. Iodinedeficiency disorders are preventable by an adequate iodine intake. In order to eliminate iodine-deficiency disorders, the World Health Assembly adopted in 1993 the strategy of universal salt iodization as proposed by the WHO and UNICEF. In the early beginning the impact indicator of this strategy was the prevalence of goitre, but impact indicators were gradually adapted to technological progress and results achieved. Currently, impact indicators are urinary iodine concentration (UIC) and the availability of iodized salt in households. With regard to the specificity of pregnant women's iodine needs, WHO set the recommended intake higher than for other adults at about $200-250 \mu \mathrm{g}$ iodine $/ \mathrm{d}^{(10)}$.

In the last five decades, in some regions of the Democratic Republic of Congo (DR Congo) the prevalence of endemic goitre was as high as $80 \%{ }^{(11)}$ and the proportion of cretinism was about $4-8 \%^{(12)}$. For nearly 20 years, universal salt iodization programmes have been adopted in the country and substantial progress has been made in the fight against iodine-deficiency disorders. The food source of iodine is basically iodized table salt. Since meat and fish are financially less accessible, the essential Fe source is vegetables, which are known to be of low availability ${ }^{(13)}$. A recent study reported very good results - availability of iodized salt in more than $95 \%$ of households in DR Congo and a goitre prevalence of less than $1 \%$ - but also the need for caution: a median UIC of $495 \mu \mathrm{g} / 1$ in school-aged children at national level ${ }^{(14,15)}$. Facing this, WHO has warned about the dangers associated with excessive iodine intake in DR Congo(16). Nevertheless it has to be noted that those results were reported from surveys conducted among school-aged children. No data are available in Congolese pregnant women, despite the increase in iodine needs in this particular group. In a study by Kitwa et al., median iodine content of table salt consumed by women in Lubumbashi was found to be between $19 \cdot 0$ and 20.5 ppm; and noniodized salt was still commercialized, as $13.9 \%$ of table salt samples had no detectable iodine ${ }^{(17)}$. In a pilot study conducted in 2007, we measured UIC in spot urine samples from fifty pregnant women attending antenatal consultations, and we observed $42 \%$ of women with UIC below $150 \mu \mathrm{g} / 1,26 \%$ with UIC between $150 \mu \mathrm{g} / \mathrm{l}$ and $249 \mu \mathrm{g} / 1,26 \%$ with UIC between $250 \mu \mathrm{g} / \mathrm{l}$ and $499 \mu \mathrm{g} / \mathrm{l}$, and $6 \%$ with UIC above $500 \mu \mathrm{g} / \mathrm{l}$ (MK Kalenga and A Robert, unpublished results). We therefore decided to conduct a survey among pregnant women in Lubumbashi, the second city of DR Congo, located in the south-east of the country. The aim of our survey was to assess iodine and Fe status in pregnant women from different socio-economic areas in Lubumbashi.

\section{Materials and methods}

\section{Participants and sample size}

Lubumbashi's population is estimated at about 1.5 million, as the last census in 1987 reported 564380 inhabitants, with a $3 \%$ increase per annum. We conducted a cross-sectional study in maternity units from three of the seven districts of Lubumbashi, representing three different socio-economic strata. We purposively selected one maternity unit in each district: (i) Lubumbashi University Clinics, located in an urban area with quite comfortable living conditions for the country; (ii) Bongonga Health Centre, located in a semiurban area with less comfortable living conditions; and (iii) Katuba General Hospital, located in a rural area with insecure living conditions. The sample size was calculated to detect an increase in median UIC of at least $50 \mu \mathrm{g} / 1$ during pregnancy, compared with non-pregnant adults, at the 0.05 significance level with a power of $80 \%$, keeping a balance between the three trimesters of pregnancy and the three maternity units. We could not weight the distribution across the three areas as the information was not available. Our sample is therefore not a simple random procedure.

Between March 2009 and February 2011, we randomly selected 375 women, 125 women in each of the three maternity units. We enrolled 225 pregnant women attending antenatal consultation, seventy-five recently delivered among $72 \mathrm{~h}$ postpartum women, and seventyfive non-pregnant women among visitors. All the women were asked to participate in the study; the recruitment continued until we had completed the sample. All recruited women participated only once in the study. Exclusion criteria were a known and treated thyroid disease and twin pregnancies. The women did not take iodine supplements during pregnancy.

The study protocol was approved by the Ethical Committee of the University of Lubumbashi (Comite d'Ethique Médicale de l'Université de Lubumbashi, no. UNILU/CEM/006/2010). Each participant gave written informed consent.

\section{Process}

Each participant provided spot urine and blood samples and underwent a physical examination and a thyroid ultrasound. Postpartum women provided samples on day 
3 after delivery. Samples were stored at $-20^{\circ} \mathrm{C}$ before laboratory analyses at Lubumbashi University Clinics.

For each participant, sociodemographic, clinical and epidemiological data were recorded through a questionnaire: age, profession, marital status, weight and height, number of pregnancies, number of children, number of miscarriages, abortions or stillbirths, history of goitre, hypertension or diabetes, and use of drugs like amiodarone or levothyroxine.

Pregnancy was confirmed by obstetrical ultrasound. Gestational age was calculated using the date of the last menstrual period and cross-checked by ultrasound findings.

\section{Biochemical analyses}

Iodine status of the women was assessed by UIC, as a reflection of recent iodine intake ${ }^{(10,18,19)}$. UIC was measured using a method based on a modification of the Sandell-Kolthoff reaction between arsenic and cerium, after mineralization with ammonium persulfate digestion $^{(20,21)}$ and microplate reading (Multiskan EX Microplate Photometer, Primary EIA V.2.1-0; Labsystems, Thermo Scientific, Pittsburgh, PA, USA). The CV for UIC in our laboratory is $8.9 \%$ at 10 (SD 1) $\mu \mathrm{g} / 1,7 \cdot 6 \%$ at 229 (SD 17) $\mu \mathrm{g} / 1$ and $9.4 \%$ at 986 (SD 93) $\mu \mathrm{g} / \mathrm{l}$.

The WHO's epidemiological criteria for assessing iodine nutrition were used ${ }^{(10)}$. For pregnant women, median $\mathrm{UIC}=150-249 \mu \mathrm{g} / \mathrm{l}$ defined an adequate iodine intake, median UIC $<150 \mu \mathrm{g} / \mathrm{l}$ defined insufficient iodine intake, median UIC $=250-499 \mu \mathrm{g} / \mathrm{l}$ defined iodine intake above requirements, and median UIC $\geq 500 \mu \mathrm{g} / 1$ defined excessive iodine intake. For non-pregnant and postpartum women, median UIC $=100-199 \mu \mathrm{g} / \mathrm{l}$ defined adequate iodine intake. We also reported the proportions of women with UIC $<50 \mu \mathrm{g} / \mathrm{l}$.

Fe deficiency was based on the measurement of serum ferritin concentration ${ }^{(6,19,22)}$. Serum ferritin was measured by immunoenzymatic assay (DiaMetra, Foligno (PG), Italy), with a reference range of $12-180 \mathrm{ng} / \mathrm{ml}$ in pregnant women and $15-200 \mathrm{ng} / \mathrm{ml}$ in non-pregnant women.

As strongly recommended, the laboratory participated in an external quality control programme. A Belgian expert from the Université Catholique de Louvain trained and supervised local laboratory technicians, and calibrated and controlled analyses performed in Lubumbashi, to ensure adherence to principles of good laboratory practice.

\section{Thyroid echography}

Thyroid gland ultrasonography was performed using a $7 \cdot 5 \mathrm{MHz}$ probe. Thyroid volume was defined by summing volumes of the lobes, and adding the isthmus volume when increased. Each volume was equal to width $\times$ height $\times$ length $\times 0.52$. A volume $>18 \mathrm{ml}$ was considered as a goitre ${ }^{(23)}$. A physician trained in obstetrical and thyroid ultrasonography at the Université Catholique de Louvain performed the ultrasonography under the supervision of a Belgian obstetrics professor.

\section{Statistical analysis}

Sample size was computed using PASS 2005 software $^{(24)}$. Continuous data are reported as arithmetic means and standard deviations when normally distributed, as geometric means and standard deviations when log-normally distributed, and as medians with interquartile ranges (IQR) in other cases. Discrete data are reported as proportions. We used Pearson's $\chi^{2}$ tests to compare proportions, Student $t$ tests or ANOVA with $F$ tests to compare means, and Mann-Whitney $U$ or ANOVA with Kruskal-Wallis tests to compare medians. The Cochran-Armitage trend test was applied to assess the tendency of iodine and Fe deficiency to increase with trimester of pregnancy. Pearson correlation coefficients were used to address the association between UIC and continuous variables. The significance level was set to $0 \cdot 05$. All statistical analyses were performed using the SAS statistical software package version $9 \cdot 3$.

\section{Results}

\section{Sample}

The average age of recruited women varied from 25 to 35 years (Table 1). In each maternity unit, pregnant women had comparable age between trimesters of pregnancy. Women in the urban area were 3 years older than women in the other areas. Control non-pregnant women were 5 years older than pregnant women, but with much greater dispersion around the mean. Mean weight of women in the semi-urban area was abnormally low in the third trimester, for similar heights in the first and second trimesters. The number of previous pregnancies was similar in all groups, except in controls from the rural area who had fewer pregnancies than the others; control women were also more often students and unmarried. Few women in each group had a family history of goitre. We did not find any case of hypertension or diabetes, and no woman used amiodarone or levothyroxine.

\section{Iodine status and thyroid volume}

The overall median UIC of pregnant women was $138 \mu \mathrm{g} / 1$ (Table 2), which is below the WHO cut-off for iodine sufficiency in pregnancy $(150 \mu \mathrm{g} / \mathrm{l})$. Median UIC indicated overload or adequate iodine intake in the first trimester, adequate or deficient iodine intake in the second, and deficient iodine intake in the third trimester in all maternity units.

Without consideration of trimesters of pregnancy, iodine status of the pregnant women was slightly different according to area of recruitment: it was adequate in the urban area (median UIC $=167$ (IQR 118-220) $\mu \mathrm{g} / \mathrm{l}$ ), mildly deficient in the semi-urban area (median UIC $=145(\mathrm{IQR}$ 92-200) $\mu \mathrm{g} / \mathrm{l}$ ) and moderately deficient in the rural area (median UIC $=95(\mathrm{IQR} 81-148) \mu \mathrm{g} / \mathrm{l}), P=0 \cdot 04$.

As shown in Table 2, the proportion of pregnant women with UIC $<50 \mu \mathrm{g} / 1$ increased from the first to the 
Table 1 Characteristics of the pregnant, postpartum and control women in the three different socio-economic areas of Lubumbashi, Democratic Republic of Congo, March 2009 to February 2011

\begin{tabular}{|c|c|c|c|c|c|c|c|c|c|c|c|}
\hline & \multicolumn{2}{|c|}{ T1 } & \multicolumn{2}{|c|}{$\mathrm{T} 2$} & \multicolumn{2}{|c|}{ T3 } & \multicolumn{2}{|c|}{ PP } & \multicolumn{2}{|c|}{ CT } & \multirow[b]{2}{*}{$P$ value* } \\
\hline & Mean & SD & Mean & SD & Mean & SD & Mean & SD & Mean & SD & \\
\hline Rural area $(n)$ & 25 & & 25 & & 25 & & 25 & & 25 & & \\
\hline Age (years) & 26 & 6 & 25 & 7 & 26 & 7 & 27 & 6 & 30 & 7 & $0 \cdot 80$ \\
\hline Height $(\mathrm{cm})$ & 162 & 6 & 163 & 8 & 163 & 7 & 159 & 7 & 166 & 7 & 0.92 \\
\hline Weight (kg) & 58 & 10 & 62 & 11 & 68 & 12 & 60 & 8 & 62 & 8 & 0.005 \\
\hline No. of pregnancies (median, IQR) & 4 & $2-6$ & 3 & $2-5$ & 3 & $2-6$ & 3 & $2-6$ & 0 & $0-7$ & $0 \cdot 87$ \\
\hline Gestational age (weeks) & 9 & 3 & 20 & 3 & 33 & 4 & & & & & \\
\hline Married (\%) & 96 & & 100 & & 100 & & 96 & & 48 & & \\
\hline \multicolumn{12}{|l|}{ Profession (\%) } \\
\hline Housewife & 48 & & 64 & & 60 & & 64 & & 40 & & \\
\hline Shopkeeper & 36 & & 28 & & 32 & & 24 & & 16 & & \\
\hline Salaried & 8 & & 8 & & 8 & & 8 & & 20 & & \\
\hline Student & 8 & & 0 & & 0 & & 4 & & 24 & & \\
\hline Goitre in family $(n)$ & 1 & & 0 & & 4 & & 0 & & 4 & & \\
\hline Semi-urban area $(n)$ & 26 & & 24 & & 25 & & 25 & & 25 & & \\
\hline Age (years) & 28 & 6 & 26 & 6 & 25 & 6 & 27 & 8 & 32 & 8 & 0.26 \\
\hline Height $(\mathrm{cm})$ & 161 & 7 & 164 & 7 & 164 & 6 & 161 & 6 & 162 & 7 & 0.32 \\
\hline Weight (kg) & 62 & 8 & 60 & 10 & 57 & 9 & 63 & 8 & 59 & 8 & 0.25 \\
\hline No. of pregnancies (median, IQR) & 4 & $2-6$ & 3 & $1-6$ & 3 & $1-5$ & 4 & $2-7$ & 4 & $1-8$ & 0.23 \\
\hline Gestational age (weeks) & 9 & 2 & 22 & 3 & 31 & 3 & & & & & \\
\hline Married (\%) & 96 & & 100 & & 100 & & 96 & & 76 & & \\
\hline \multicolumn{12}{|l|}{ Profession (\%) } \\
\hline Housewife & 50 & & 71 & & 64 & & 60 & & 48 & & \\
\hline Shopkeeper & 42 & & 29 & & 32 & & 40 & & 40 & & \\
\hline Salaried & 8 & & 0 & & 4 & & 0 & & 8 & & \\
\hline Student & 0 & & 0 & & 0 & & 0 & & 4 & & \\
\hline Goitre in family $(n)$ & 2 & & 0 & & 2 & & 2 & & 2 & & \\
\hline Urban area $(n)$ & 25 & & 22 & & 28 & 25 & & & 25 & & \\
\hline Age (years) & 31 & 7 & 28 & 7 & 29 & 7 & 27 & 7 & 35 & 9 & 0.45 \\
\hline Height $(\mathrm{cm})$ & 165 & 6 & 164 & 4 & 164 & 4 & 161 & 7 & 163 & 5 & 0.79 \\
\hline Weight $(\mathrm{kg})$ & 60 & 12 & 65 & 12 & 69 & 9 & 66 & 16 & 64 & 13 & 0.02 \\
\hline No. of pregnancies (median, IQR) & 3 & $1-7$ & 4 & $1-6$ & 4 & $1-7$ & 3 & $1-5$ & 4 & $1-8$ & 0.98 \\
\hline Gestational age (weeks) & 9 & 2 & 20 & 3 & 32 & 4 & & & & & \\
\hline Married (\%) & 96 & & 100 & & 100 & & 96 & & 60 & & \\
\hline \multicolumn{12}{|l|}{ Profession (\%) } \\
\hline Housewife & 48 & & 72 & & 78 & & 76 & & 24 & & \\
\hline Shopkeeper & 32 & & 14 & & 11 & & 12 & & 16 & & \\
\hline Salaried & 16 & & 14 & & 7 & & 8 & & 40 & & \\
\hline Student & 4 & & 0 & & 4 & & 4 & & 20 & & \\
\hline Goitre in family $(n)$ & 2 & & 2 & & 1 & & 1 & & 1 & & \\
\hline
\end{tabular}

T1, first trimester, T2, second trimester, T3, third trimester, PP, postpartum, CT, control non-pregnant; IQR, interquartile range. Rural area, General Hospital of Katuba; semi-urban area, Bongonga Health Centre; urban area, Lubumbashi University Clinics. Data are presented as means and standard deviations, or numbers, or medians and IQR, or percentages as indicated.

${ }^{*}$ One-way ANOVA $P$ value: compares means through trimesters of pregnancy.

third trimester and the trend test was significant in all settings. These proportions were particularly high in semi-urban and rural areas compared with the urban area.

Women in postpartum and in the control group had adequate iodine intake; with median UIC significantly higher than that of women in the third trimester of pregnancy in rural and semi-urban areas, but not significantly so in the urban area. Median UIC values in the first trimester of pregnancy were higher than in the nonpregnant group, but the difference was not statistically significant (Mann-Whitney $U: P=0.50,0.33$ and 0.49 , respectively, in rural, semi-urban and urban areas).

In the overall sample, we found $52 \cdot 3 \%(115 / 220)$ of pregnant women with UIC below $150 \mu \mathrm{g} / \mathrm{l}$. Figure 1 shows the distribution of UIC in pregnant women from the three different areas and by trimester of pregnancy. Proportions of pregnant women with UIC $<150 \mu \mathrm{g} / 1$ were higher in the second and third trimesters compared with the first, and lower in the urban area compared with the semi-urban and rural areas: in the first, second and third trimester respectively $29 \%, 84 \%$ and $72 \%$ in the rural area; $33 \%$, $42 \%$ and $76 \%$ in the semi-urban area; and 30\%, $41 \%$ and $57 \%$ in the urban area. UIC was therefore negatively correlated with gestational age: $r=-0 \cdot 24, P<0 \cdot 001$ (Fig. 2).

The mean thyroid volume was in the normal range for all subgroups of women (Table 3). However, twenty-three women had goitre and some of them had also a thyroid nodule. Proportions of goitre varied between $0 \%$ and $8 \%$ in pregnant women, and between $0 \%$ and $16 \%$ in nonpregnant women, without significant difference between areas of recruitment and subgroups of women. Goitre was not associated with UIC (Mann-Whitney $U: P=0 \cdot 90)$. 
Table 2 Distribution of urinary iodine concentration (UIC) in pregnant, postpartum and control women, Lubumbashi, Democratic Republic of Congo, March 2009 to February 2011

\begin{tabular}{|c|c|c|c|c|c|c|}
\hline & \multirow[b]{2}{*}{$n$} & \multicolumn{3}{|c|}{ UIC ( $\mu \mathrm{g} / \mathrm{l})$} & \multirow[b]{2}{*}{$P$ trend $^{*}$} & \multirow[b]{2}{*}{$P$ valuet } \\
\hline & & Median & IQR & $\%<50 \mu \mathrm{g} / \mathrm{l}$ & & \\
\hline \multicolumn{7}{|l|}{ Overall } \\
\hline Pregnant & 220 & 138 & $105-172$ & $23 \cdot 2$ & & \\
\hline Postpartum & 75 & 144 & $127-176$ & $12 \cdot 0$ & & \\
\hline Non-pregnant & 73 & 204 & $146-275$ & $10 \cdot 9$ & & 0.09 \\
\hline \multicolumn{7}{|l|}{ Rural area } \\
\hline All pregnant & 73 & 95 & $81-148$ & $33 \cdot 8$ & & \\
\hline $\mathrm{T} 1$ & 24 & 255 & $122-348$ & $12 \cdot 5$ & & \\
\hline T2 & 25 & 70 & $0-100$ & $48 \cdot 0$ & & \\
\hline T3 & 25 & 88 & $21-231$ & $40 \cdot 0$ & 0.001 & \\
\hline Postpartum & 25 & 172 & 88-382 & $12 \cdot 0$ & & \\
\hline Control & 25 & 176 & $94-328$ & $8 \cdot 3$ & & $<0.001$ \\
\hline \multicolumn{7}{|l|}{ Semi-urban area } \\
\hline All pregnant & 73 & 145 & $92-200$ & $21 \cdot 9$ & & \\
\hline $\mathrm{T} 1$ & 24 & 306 & $115-463$ & $4 \cdot 2$ & & \\
\hline T2 & 24 & 166 & 89-314 & $12 \cdot 5$ & & \\
\hline T3 & 25 & 68 & $17-136$ & $48 \cdot 0$ & 0.001 & \\
\hline Postpartum & 25 & 147 & $122-182$ & $8 \cdot 0$ & & \\
\hline Control & 25 & 256 & $127-343$ & $8 \cdot 0$ & & $<0.001$ \\
\hline \multicolumn{7}{|l|}{ Urban area } \\
\hline All pregnant & 73 & 167 & $118-220$ & $13 \cdot 7$ & & \\
\hline $\mathrm{T} 1$ & 23 & 203 & $100-326$ & $8 \cdot 7$ & & \\
\hline T2 & 22 & 174 & $110-452$ & $0 \cdot 0$ & & \\
\hline T3 & 28 & 99 & 44-279 & $28 \cdot 6$ & 0.02 & \\
\hline Postpartum & 25 & 138 & $68-279$ & $16 \cdot 0$ & & \\
\hline Control & 24 & 147 & 85-339 & $16 \cdot 7$ & & $0 \cdot 15$ \\
\hline
\end{tabular}

\section{Iron status and related iodine status}

More than $25 \%$ of women (58/225) were Fe-deficient, with serum ferritin $<12 \mathrm{ng} / \mathrm{ml}$. The geometric means of serum ferritin values were low in the three areas but still in the normal reference range, except in the third trimester of pregnancy in the rural area (Table 3). We found a negative association between serum ferritin values and gestational age $(r=-0 \cdot 28, P<0 \cdot 001)$.

The proportion of pregnant women who were at the same time Fe- and iodine-deficient increased with trimester of pregnancy in all three maternity units, and the trend test was statistically significant in all settings.

Serum ferritin was correlated with UIC in pregnant women (iodine $=174+0 \cdot 83 \times$ ferritin; $r=0 \cdot 14, P=0 \cdot 02$ ), reflecting a direct relationship between low serum ferritin and low UIC.

We did not find any other correlation between UIC or ferritin and other characteristics of participants.

\section{Discussion}

In the present study we found that the iodine status of pregnant women in Lubumbashi, DR Congo was just below the cut-off for sufficiency, with median UIC at $138 \mu \mathrm{g} / \mathrm{l}$. Pregnant women in the third and second trimesters had lower UIC than women in the first trimester in all maternity units. Median UIC of pregnant women in the first trimester was higher than that of non-pregnant women and this result was constant across areas.

Almost half of pregnant women in the first trimester (37/71) had UIC higher than adequate, $v$. a quarter $(19 / 71)$ in the second trimester and a fifth (17/78) in the third trimester. This corresponds to an excessive iodine intake or above requirements. Iodine intake can protect against iodine-deficiency disorders when sufficient; but excessive intake can induce disorders like hypothyroidism $^{(25)}$, thyrotoxicosis, hyperthyroidism ${ }^{(26)}$ and autoimmune thyroid diseases ${ }^{(10)}$. This is a public health concern and there is need for a more rigorous public health policy in monitoring and regulating iodine intake in the DR Congo population. However, the higher proportion of excessive UIC in the first trimester can be explained by the increase in renal clearance that appears in early pregnancy ${ }^{(27)}$. Without an adequate iodine intake, the increased glomerular filtration rate could deplete body iodine stores entirely in pregnant women $^{(28)}$. Therefore, a higher median UIC in the first trimester could have a different meaning than later in pregnancy, and could be misinterpreted as indicating adequate iodine intake, while corresponding only with an increased iodine renal clearance related to the hormonal 

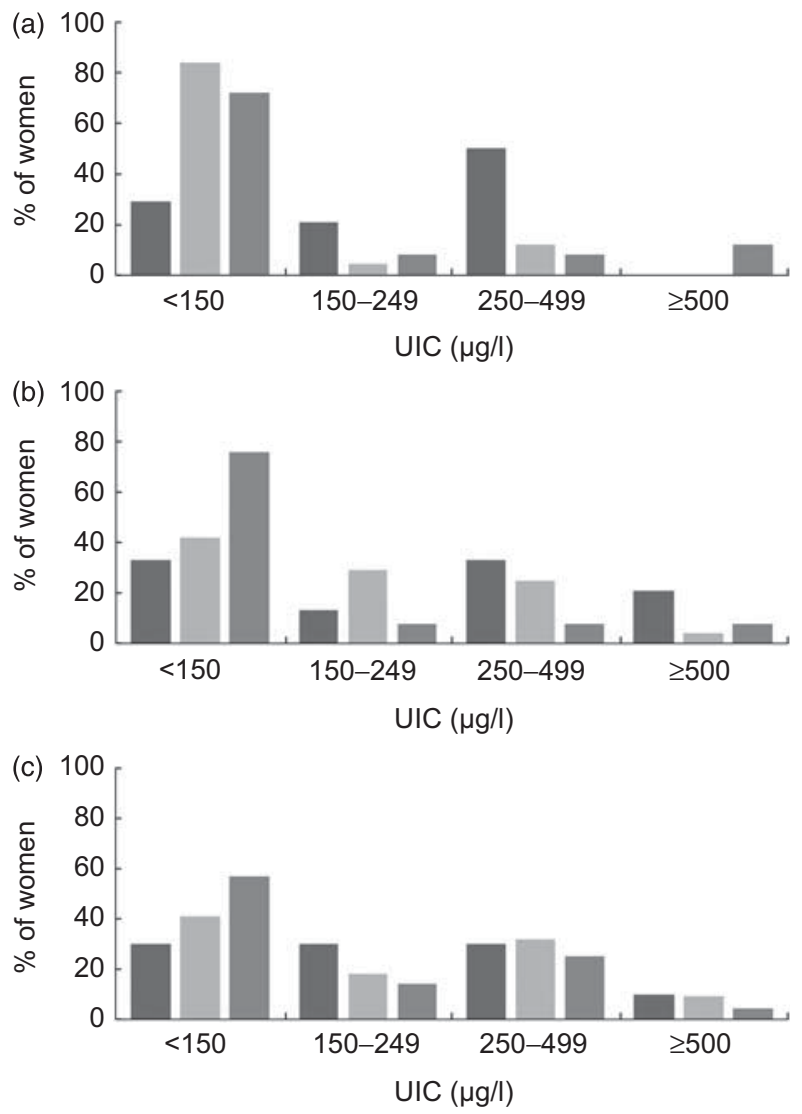

Fig. 1 Distribution of urinary iodine concentration (UIC) by trimester of pregnancy ( $\square$, first trimester;, , second trimester; $\square$, third trimester) in pregnant women ( $n$ 225) from three maternity units in Lubumbashi, Democratic Republic of Congo, March 2009 to February 2011: (a) rural area (General Hospital of Katuba); (b) semi-urban area (Bongonga Health Centre); (c) urban area (Lubumbashi University Clinics)

milieu in early pregnancy. Consequently, it seems important to define cut-off values of median UIC more precisely, with specific values for each trimester of pregnancy.

Iodine status of the pregnant women was quite different in the three areas of recruitment: adequate in the urban area, mildly deficient in the semi-urban area and moderately deficient in the rural area.

Postpartum women had on average adequate iodine intake; their median UIC $(144 \mu \mathrm{g} / \mathrm{l})$ was higher than the overall median UIC of pregnant women $(138 \mu \mathrm{g} / \mathrm{l})$ but still remained lower than in controls $(204 \mu \mathrm{g} / \mathrm{l})$. Unfortunately, we did not check the use of iodized antiseptics for each woman in the present study. Povidone-iodine, an iodinebased antiseptic, is still used in Lubumbashi to disinfect the perineal region during delivery, and also after delivery in the case of episiotomy. This could have induced an increase in postpartum UIC. We do not know the actual proportion who breast-fed their children in these recently delivered women and it may be iodine excretion in breast milk is not yet so effective. The exclusive breast-feeding rate in DR Congo is about $46 \%$ at 4 months.

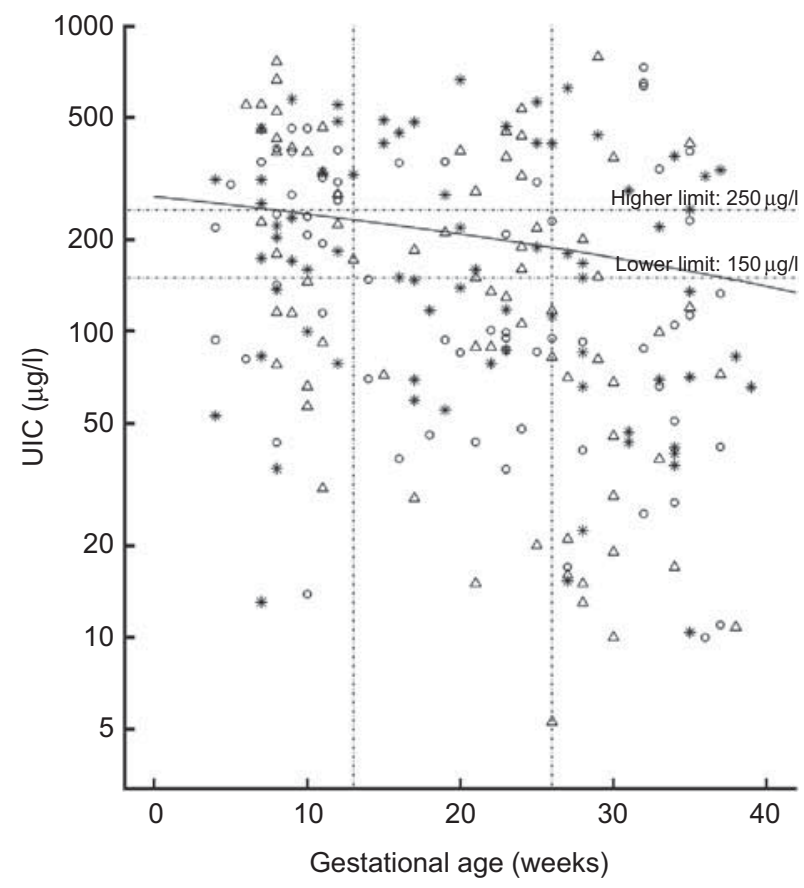

Fig. 2 Correlation between urinary iodine concentration (UIC) and gestational age in pregnant women from three maternity units in Lubumbashi, Democratic Republic of Congo, March 2009 to February 2011: $\bigcirc$, rural area (General Hospital of Katuba); $\triangle$, semi-urban area (Bongonga Health Centre); $*$, urban area (Lubumbashi University Clinics). Vertical dashed lines correspond to the end of the first and second trimesters of pregnancy; horizontal dashed lines represent the lower and the higher limits for adequate iodine intake in pregnant women, 150 and $250 \mu \mathrm{g} / \mathrm{l}$. Correlation is significant: $r=-0.24, P<0.001$ ( $n$ 219)

To detect Fe deficiency we measured serum ferritin concentration, which indicates Fe stores in the absence of inflammation ${ }^{(6,19,22)}$. Ferritin values were low despite means in the normal range. One pregnant woman in six was both $\mathrm{Fe}$ - and iodine-deficient, with this rising to almost one in three pregnant women in the rural area.

In the present study we found much more severe deficiencies in the rural area, both in iodine and Fe status. The rural area has a very precarious population compared with the urban and semi-urban areas, which have quite better socio-economic status. This suggests a control strategy more attentive to rural specificities.

In our survey we found a higher prevalence of goitre than in the general population, which is $<1 \%{ }^{(14)}$, but we did not find goitre prevalence specific to pregnant women or women of childbearing age with which to compare our results. There was no association in our study between goitre and Fe deficiency or iodine deficiency in pregnant women.

The strengths of our study include the analysis of pregnant women in different periods of gestation, with balanced groups in the first, second and third trimesters of pregnancy; the comparison with non-pregnant women and women in postpartum; and moreover an external control of quality for biochemical analyses and ultrasonography 
Table 3 Serum ferritin concentration, thyroid volume and presence of nodules in pregnant, postpartum and control women, Lubumbashi, Democratic Republic of Congo, March 2009 to February 2011

\begin{tabular}{|c|c|c|c|c|c|c|c|c|c|}
\hline & \multirow[b]{2}{*}{$n$} & \multicolumn{3}{|c|}{ Serum ferritin (ng/ml) } & \multirow[b]{2}{*}{$\%$ deficit in iodine \& Fe } & \multicolumn{4}{|c|}{ Thyroid volume (ml) } \\
\hline & & Mean & SD & $\%$ deficient & & Mean & SD & $>18 \mathrm{ml}(n)$ & Nodule $(n)$ \\
\hline \multicolumn{10}{|l|}{ Overall } \\
\hline Pregnant & 225 & $21 \cdot 0$ & $2 \cdot 5$ & $39 \cdot 1$ & $21 \cdot 8$ & $10 \cdot 4$ & $1 \cdot 4$ & 18 & 11 \\
\hline Postpartum & 75 & $28 \cdot 1$ & $2 \cdot 2$ & $21 \cdot 3$ & $5 \cdot 3$ & $12 \cdot 6$ & $1 \cdot 3$ & 22 & 6 \\
\hline Non-pregnant & 75 & $27 \cdot 0$ & 1.9 & $21 \cdot 3$ & $5 \cdot 3$ & $11 \cdot 5$ & $1 \cdot 3$ & 5 & 6 \\
\hline \multicolumn{10}{|l|}{ Rural area } \\
\hline T1 & 24 & $28 \cdot 1$ & $2 \cdot 5$ & $28 \cdot 0$ & $12 \cdot 5$ & $11 \cdot 0$ & $1 \cdot 4$ & 2 & 2 \\
\hline $\mathrm{T} 2$ & 25 & $13 \cdot 2$ & $2 \cdot 1$ & $60 \cdot 0$ & $44 \cdot 0$ & $10 \cdot 0$ & $1 \cdot 4$ & 2 & 0 \\
\hline${ }^{\mathrm{T} 3} P$ trend $^{*}$ & 25 & $8 \cdot 9$ & $2 \cdot 0$ & $\begin{array}{c}56 \cdot 0 \\
0.02\end{array}$ & $\begin{array}{c}40 \cdot 0 \\
0.02\end{array}$ & $9 \cdot 6$ & $1 \cdot 4$ & 0 & 3 \\
\hline Postpartum & 25 & $26 \cdot 4$ & $2 \cdot 2$ & $20 \cdot 0$ & $8 \cdot 0$ & $12 \cdot 8$ & $1 \cdot 3$ & 2 & 1 \\
\hline $\begin{array}{l}\text { Control } \\
P \text { valuet }\end{array}$ & 24 & $\begin{array}{l}23 \cdot 4 \\
<0 \cdot 001\end{array}$ & $1 \cdot 7$ & $28 \cdot 0$ & $4 \cdot 2$ & $\begin{array}{c}11.5 \\
0.02\end{array}$ & $1 \cdot 4$ & 2 & 9 \\
\hline \multicolumn{10}{|l|}{ Semi-urban area } \\
\hline $\mathrm{T} 1$ & 24 & $32 \cdot 8$ & $2 \cdot 4$ & 3.9 & 0.0 & $10 \cdot 6$ & $1 \cdot 4$ & 0 & 3 \\
\hline T2 & 24 & $15 \cdot 1$ & $1 \cdot 6$ & $20 \cdot 8$ & $4 \cdot 2$ & $10 \cdot 1$ & $1 \cdot 4$ & 1 & 3 \\
\hline${ }^{\text {T3 }} P$ trend ${ }^{*}$ & 25 & $21 \cdot 5$ & $2 \cdot 9$ & $\begin{array}{l}20 \cdot 0 \\
0.02\end{array}$ & $\begin{array}{c}12 \cdot 0 \\
0 \cdot 02\end{array}$ & $10 \cdot 0$ & $1 \cdot 4$ & 1 & 1 \\
\hline Postpartum & 25 & $33 \cdot 3$ & $2 \cdot 6$ & $24 \cdot 0$ & $4 \cdot 0$ & $11 \cdot 4$ & $1 \cdot 3$ & 0 & 3 \\
\hline $\begin{array}{l}\text { Control } \\
P \text { valuet }\end{array}$ & 25 & $\begin{array}{l}29.5 \\
0.004\end{array}$ & $2 \cdot 0$ & $20 \cdot 0$ & $8 \cdot 0$ & $\begin{array}{l}11 \cdot 6 \\
0.33\end{array}$ & $1 \cdot 4$ & 2 & 5 \\
\hline \multicolumn{10}{|l|}{ Urban area } \\
\hline $\mathrm{T} 1$ & 23 & $29 \cdot 2$ & $2 \cdot 3$ & $8 \cdot 0$ & $0 \cdot 0$ & $10 \cdot 1$ & $1 \cdot 5$ & 2 & 3 \\
\hline $\mathrm{T} 2$ & 22 & $30 \cdot 8$ & $2 \cdot 3$ & $13 \cdot 6$ & $4 \cdot 6$ & $11 \cdot 2$ & $1 \cdot 4$ & 1 & 1 \\
\hline T3 & 28 & $24 \cdot 4$ & $2 \cdot 0$ & $21 \cdot 4$ & $17 \cdot 9$ & $10 \cdot 7$ & $1 \cdot 7$ & 2 & 2 \\
\hline$P$ trend $^{*}$ & & & & 0.08 & 0.01 & & & & \\
\hline Postpartum & 25 & $25 \cdot 2$ & $1 \cdot 9$ & $20 \cdot 0$ & $4 \cdot 0$ & $13 \cdot 9$ & $1 \cdot 3$ & 4 & 1 \\
\hline $\begin{array}{l}\text { Control } \\
P \text { valuet }\end{array}$ & 24 & $\begin{array}{l}28 \cdot 0 \\
0.76\end{array}$ & $2 \cdot 0$ & $16 \cdot 0$ & $4 \cdot 2$ & $\begin{array}{l}11 \cdot 3 \\
0.04\end{array}$ & $1 \cdot 3$ & 2 & 8 \\
\hline
\end{tabular}

T1, first trimester, T2, second trimester, T3, third trimester.

Rural area, General Hospital of Katuba; semi-urban area, Bongonga Health Centre; urban area: Lubumbashi University Clinics.

Data are presented as geometric means and standard deviations, or percentages or numbers as indicated.

*Trend test $P$ value: compares proportions of deficiency through trimesters of pregnancy.

tOne-way ANOVA $P$ value: compares means between all five groups of women.

which increases the validity of our data. Our study has some limitations. Our sample is a non-probability sampling; this can be viewed as a limitation to the representativeness of all pregnant women from Lubumbashi, and then to the external validity of the study. The cross-sectional design did not allow us to assess longitudinal time trends during pregnancy; nevertheless, our results suggest clearly such time trends in iodine and Fe deficiencies during pregnancy. The recruitment of lactating women later after delivery could have allowed us to better compare iodine status in pregnant and postpartum women. Finally, we could not interpret our results on an individual level as we analysed one spot urine sample per woman.

Some other studies found more marked results than ours, with severe iodine deficiency in pregnant women. A study of the iodine demand in pregnant women from the urban area of Rome in Italy by Marchioni et al. reported a median UIC of $74 \mu \mathrm{g} / \mathrm{l}$, compared with $182 \mu \mathrm{g} / \mathrm{l}$ in non-pregnant women, showing a very high proportion of iodine deficiency in pregnant women $(92 \%)^{(29)}$. Their results are however more alarming than ours, particularly because they studied only pregnant women in the first trimester. Another recent study in Australian pregnant women by Charlton et al. found a very low median UIC of $87 \cdot 5 \mu \mathrm{g} / \mathrm{l}$ with $15 \%$ of pregnant women having UIC below $50 \mu \mathrm{g} / \mathrm{l}^{(30)}$. More than $80 \%$ of the participants in that study were in the third trimester of pregnancy, and only $2 \%$ were in the fist trimester. Charlton et al. found a median UIC of $77 \mu \mathrm{g} / \mathrm{l}$ in the third trimester, close to our findings at the third trimester of pregnancy.

In countries where dietary iodine intake is adequate in pregnant women as well as in the general population, iodine fortification of salt has been done for several decades with good regulation or the soil is rich in iodine thanks to the geographical situation near the ocean. Nevertheless, iodine nutrition has to be monitored constantly; otherwise iodine intake could rapidly and significantly decrease. For example, in the USA, where adequate iodine intake has been reported for many years, a significant decrease in median UIC was noticed from one survey in 1971-1974 to another in 1988-1994 ${ }^{(31)}$. However, the study based on the 2003-2004 National Health and Nutrition Examination Survey showed a higher median UIC in pregnant women than in non-pregnant women of childbearing age, $166 \mu \mathrm{g} / 1$ v. $123 \mu \mathrm{g} / \mathrm{l}$, and $9 \%$ of women had UIC below $50 \mu \mathrm{g} / 1$. Caldwell et al. concluded that their results underlined the adequate iodine nutrition in the US population ${ }^{(32)}$.

A recent study in Mexican pregnant women found median UIC values slightly above requirements in pregnant 
women of the first and second trimester, and adequate median UIC in the third trimester. Garcia-Solis et al. explained their findings by the fact that iodized salt plays an important role in sustaining iodine nutrition in pregnant women ${ }^{(33)}$.

In a study on iodine content of salt table that we conducted with our colleagues in Lubumbashi, Kitwa et al. found that median iodine content was lower than the minimum threshold of $15 \mathrm{ppm}$ in $>36 \%$ of samples, and that there was still non-iodized salt commercialized in Lubumbashi ${ }^{(17)}$. They also found lower iodine content values in rural areas: the proportion of non-iodized salt commercialized was greater than in urban and semiurban areas.

Studies on iodine status are usually based on data about the availability of iodized salt in households and median UIC measured in school-aged children, or serum thyrotropin measured in newborns. In other key groups like women of childbearing age and pregnant women, data are generally lacking, except in some countries where recent studies have deliberately focused on those groups. Nevertheless, when available, data on iodine status generally show discrepancies between this particular category of pregnant women and other groups in the general population: iodine intake is usually adequate in children of school age while it is deficient in pregnant women, as reported in Thai pregnant women ${ }^{(34)}$. A few countries have shown similar findings in pregnant women and the general population, as in Switzerland, the USA and Bulgaria, or Iran and China ${ }^{(16,35,36)}$. It should be noted that most of these countries with concordant results between pregnant women and the general population adopted salt iodization programmes a long time ago (Switzerland in 1922, USA in 1924, Bulgaria in 1958) ${ }^{(37)}$. In a recent literature review on iodine status which included surveys that took into account - as well as pregnant women and school-aged children - also pregnant women $v$. non-pregnant women, Wong et al. came to the conclusion that the iodine status of pregnant women has to be addressed by considering pregnant women separately ${ }^{(38)}$.

Our study also revealed high proportions of $\mathrm{Fe}$ deficiency in pregnant women: $13 \%$ in the first, $31 \%$ in the second and $32 \%$ in the third trimester. In a study on the effect of Fe supplementation in pregnancy and its impact on newborns in Niger, Preziosi et al. found $54 \%$ of women to be Fe-deficient at 6 months of pregnancy ${ }^{(39)}$, which is more severe than our results. A recent study in Spain found Fe deficiency among $20 \%$ of pregnant women in the first trimester, $54 \%$ in the second and $66 \%$ in the third, which is also more than in our study ${ }^{(40)}$. In a study on Swiss pregnant women ${ }^{(9)}$, Zimmermann et al. found 16\% to be Fe-deficient in the second trimester and $40 \%$ in the third, but they considered a less restrictive cut-off than us. If we had considered the same cut-off of serum ferritin concentration, the proportions of Fe-deficient pregnant women would have increased to $31 \%, 41 \%$ and $51 \%$ in the first, second and third trimester, respectively, in our study. In general, proportions of Fe deficiency during pregnancy are high and could justify a strategy of systematic supplementation early in pregnancy or even in women of childbearing age. Fe supplementation improves Fe status, and the benefit is for all pregnant women, regardless of their Fe status before pregnancy, even if the evidence for and magnitude of its positive impact on children remain to be proved.

A major point of our study is the high proportion of pregnant women with deficiency in both iodine and Fe, reflecting their poor nutritional status. We hope to assess the thyroid function of these pregnant women, and later to follow up their offspring, as iodine sufficiency is important for the mother's thyroid function and the child's neurocognitive development.

\section{Conclusion}

The present study suggests that pregnant women are at risk of iodine and Fe deficiency in Lubumbashi, DR Congo, especially in late pregnancy. Efforts need to be pursued in order to eliminate these nutrient deficiencies, and reduce related disorders, especially through $\mathrm{Fe}$ and iodine supplementation and through better promotional programmes of nutrition during pregnancy.

\section{Acknowledgements}

Sources of funding: This study was supported by a grant from the Commission Universitaire pour le Développement (CUD - PIC 2008 RD Congo, www.cud.be) of the Belgian Government. Conflicts of interest: The authors have no conflicts of interest. Authors' contributions: L.H. was involved in study design, data collection, statistical analysis, data interpretation and manuscript writing; A.R. designed and obtained the funding for the overall study, supervised the study in Belgium and was involved in data interpretation; M.K.K. was involved in the study design and was the local coordinator of the study in Lubumbashi; P.D.N. was involved in the study design; K.E.T. collected data and performed laboratory measurements and ultrasonography examinations; P.W. supervised the laboratory measurements; C.D. and P.D. provided critical advice in manuscript preparation. All authors have reviewed and approved the paper. L.H. and A.R. had primary responsibility for the final content.

\section{References}

1. Hetzel BS (1989) The Story of Iodine Deficiency: An International Challenge in Nutrition. Delhi: Oxford University Press.

2. Glinoer D (2007) The importance of iodine nutrition during pregnancy. Public Health Nutr 10, 1542-1546. 
3. Hess SY (2010) The impact of common micronutrient deficiencies on iodine and thyroid metabolism: the evidence from human studies. Best Pract Res Clin Endocrinol Metab 24, 117-132.

4. Andersson M, Thankachan P, Muthayya S et al. (2008) Dual fortification of salt with iodine and iron: a randomized, double-blind, controlled trial of micronized ferric pyrophosphate and encapsulated ferrous fumarate in southern India. Am J Clin Nutr 88, 1378-1387.

5. Bothwell TH (2000) Iron requirements in pregnancy and strategies to meet them. Am J Clin Nutr 72, 1 Suppl., 257S-264S.

6. Milman N (2006) Iron and pregnancy - a delicate balance. Ann Hematol 85, 559-565.

7. Stoltzfus RJ (2011) Iron interventions for women and children in low-income countries. J Nutr 141, issue 4, 756S-762S.

8. Allen LH (2005) Multiple micronutrients in pregnancy and lactation: an overview. Am J Clin Nutr 81, issue 5, 1206S-1212S.

9. Zimmermann MB, Burgi H \& Hurrell RF (2007) Iron deficiency predicts poor maternal thyroid status during pregnancy. J Clin Endocrinol Metab 92, 3436-3440.

10. World Health Organization, UNICEF \& International Council for the Coctrol of Iodine Deficiency Disorders (2007) Assessment of Iodine Deficiency Disorders and Monitoring their Elimination. A Guide for Programme Managers, 3rd ed. Geneva: WHO.

11. Thilly CH, Ermans AM \& Delange F (1972) Further investigations of iodine deficiency in the etiology of endemic goiter. Am J Clin Nutr 25, 30-40.

12. Thilly CH, Swennen B, Bourdoux P et al. (1993) The epidemiology of iodine-deficiency disorders in relation to goitrogenic factors and thyroid-stimulating-hormone regulation. Am J Clin Nutr 57, 2 Suppl., 267S-270S.

13. Berger J \& Dillon JC (2002) Control of iron deficiency in developing countries. Sante 12, 22-30.

14. Ntambue K (2007) From severe endemic cretinism to iodine sufficiency: an IDD success story in the Democratic Republic of the Congo. IDD Newsletter 26, issue 4, 1-4.

15. World Health Organization (2007) WHO Global Database on Iodine Deficiency. Geneva: WHO.

16. de Benoist B, McLean E, Andersson M et al. (2008) Iodine deficiency in 2007: global progress since 2003. Food Nutr Bull 29, 195-202.

17. Kitwa E, Habimana L, Lumbu JB et al. (2012) Evaluation of iodine content in table salt consumed in Lubumbashi, DR Congo. Food Nutr Bull 33, 217-223.

18. Zimmermann MB (2004) Assessing iodine status and monitoring progress of iodized salt programs. J Nutr 134, 1673-1677.

19. Zimmermann MB (2008) Methods to assess iron and iodine status. Br J Nutr 99, Suppl. 3, S2-S9.

20. Ohashi T, Yamaki M, Pandav CS et al. (2000) Simple microplate method for determination of urinary iodine. Clin Chem 46, 529-536.

21. Pino S, Fang SL \& Braverman LE (1996) Ammonium persulfate: a safe alternative oxidizing reagent for measuring urinary iodine. Clin Chem 42, 239-243.

22. Carriaga MT, Skikne BS, Finley B et al. (1991) Serum transferrin receptor for the detection of iron deficiency in pregnancy. Am J Clin Nutr 54, 1077-1081.
23. World Health Organization (1993) Indicators for Assessing Iodine Deficiency Disorders and their Control Programmes. Report of a Joint WHO/UNICEF/ICCIDD Consultation, 3-5 November 1992, p. 33. Geneva: WHO.

24. Hintze J (2011) PASS 2008 Software. Kaysville, UT: NCSS, LLC.

25. Laurberg P, Andersen S, Bjarnadottir RI et al. (2007) Evaluating iodine deficiency in pregnant women and young infants - complex physiology with a risk of misinterpretation. Public Health Nutr 10, 1547-1552.

26. Stanbury JB, Ermans AE, Bourdoux P et al. (1998) Iodineinduced hyperthyroidism: occurrence and epidemiology. Thyroid 8, 83-100.

27. Glinoer D (2004) The regulation of thyroid function during normal pregnancy: importance of the iodine nutrition status. Best Pract Res Clin Endocrinol Metab 18, 133-152.

28. Stilwell G, Reynolds PJ, Parameswaran V et al. (2008) The influence of gestational stage on urinary iodine excretion in pregnancy. J Clin Endocrinol Metab 93, 1737-1742.

29. Marchioni E, Fumarola A, Calvanese A et al. (2008) Iodine deficiency in pregnant women residing in an area with adequate iodine intake. Nutrition 24, 458-461.

30. Charlton KE, Gemming L, Yeatman H et al. (2010) Suboptimal iodine status of Australian pregnant women reflects poor knowledge and practices related to iodine nutrition. Nutrition 26, 963-968.

31. Hollowell JG \& Haddow JE (2007) The prevalence of iodine deficiency in women of reproductive age in the United States of America. Public Health Nutr 10, 1532-1539.

32. Caldwell KL, Miller GA, Wang RY et al. (2008) Iodine status of the US population, National Health and Nutrition Examination Survey 2003-2004. Thyroid 18, 1207-1214.

33. Garcia-Solis P, Solis-S JC, Garcia-Gaytan AC et al. (2011) Iodine nutrition status in pregnant women in Mexico. Thyroid 21, 1367-1371.

34. Gowachirapant S, Winichagoon P, Wyss L et al. (2009) Urinary iodine concentrations indicate iodine deficiency in pregnant Thai women but iodine sufficiency in their school-aged children. J Nutr 139, 1169-1172.

35. Azizi F (2007) Iodine nutrition in pregnancy and lactation in Iran. Public Health Nutr 10, 1596-1599.

36. Wang Y, Zhang Z, Ge P et al. (2009) Iodine deficiency disorders after a decade of universal salt iodization in a severe iodine deficiency region in China. Indian J Med Res 130, 413-417.

37. Delange F, Burgi H, Chen ZP et al. (2002) World status of monitoring iodine deficiency disorders control programs. Thyroid 12, 915-924.

38. Wong EM, Sullivan KM, Perrine CG et al. (2011) Comparison of median urinary iodine concentration as an indicator of iodine status among pregnant women, school-age children, and nonpregnant women. Food Nutr Bull 32, 206-212.

39. Preziosi P, Prual A, Galan P et al. (1997) Effect of iron supplementation on the iron status of pregnant women: consequences for newborns. Am J Clin Nutr 66, $1178-1182$.

40. Ribot B, Aranda N, Viteri F et al. (2012) Depleted iron stores without anaemia early in pregnancy carries increased risk of lower birthweight even when supplemented daily with moderate iron. Hum Reprod 27, 1260-1266. 